\title{
Review on Intensive Land Use after the 18th CPC National Congress
}

\author{
REN Ru ${ }^{1, a}$, HUANG Ying ${ }^{2, b}$ \\ ${ }^{1}$ Student of financial risk and management, Business school, University of Jinan, Shandong, China \\ ${ }^{2}$ Business School, University of Jinan, Shandong, China \\ amaxredzhonghuan@163.com, ${ }^{\mathrm{b}}$ huang-yin-2000@163.com,
}

Keywords: scarcity of land resources, intensive use of land, carbon emission

Abstract: Land resource lies in a significant position in China due to its largest population in the world. Academics in China have been studying on the topic of efficient utilization of land for gradually realizing China's economic transition without breaking the 1.8 billion mu red line of plough. A series of macro policies have been introduced during the 18th CPC National Congress, including optimization on systems of land conservation and its intensive use, strict and rational land supply for urban development and enhancement on land-use ratio. Based on above mentioned cases, this paper illustrated the core study content of "land intensive use" in three aspects and proposed viable suggestions on improvements.

\section{Introduction}

Covering approximately 9.6 million square kilometers, China is the world's third-largest country by land area. Despite China's massive size, the per capita acreage of this country reaches only up to $29 \%$ of the world average, with the $139^{\text {th }}$ rank in population intensity across the world. ${ }^{[1]}$ It has been 50 years since China implemented the family planning policy in 1966. Although this policy has slowed down China's population growth, it also brought a series of adverse impacts such as aging of population and scarcity of quality land. Furthermore, this densely populated situation in China may last for a long time. Therefore sustainable development has become an essential part in China's long-term strategic planning. At present, Chinese economy is at a crucial stage of economic and social transformation and development, which makes land resources increasingly vital. Due to emerging challenges from land extensive use, severe situations of agriculture acreage preservation and contradictions between land supply and demand, sustainable land use has become an important approach in boosting economic transformation, accelerating construction of ecological civilization, building new-type urbanization and ensuring sustainable development of China's economy and society.

\section{The connotation and mechanism of land intensive use}

Chinese scholars have reached agreements on the definition of connotation of land intensive use based on David Ricardo's theory and practical experience about land intensive evaluation. This theory states that spending on factors of production for limited area of land, both in quantity and quality, should be rationally increased in order to maximize comprehensive benefits of land use and realize its full potential on the basis of optimal allocation and structural upgrading of regional land. ${ }^{[2]}$ It is also a common perspective among Chinese academics that sustainable utilization of land resources could improve unit value created by land and extend sustainable utilization period of land, which prevents land resources from being wasted, obsoleted or even unusable. According to a 
range of statistics including national population and per capita grain supply level, the concept of 1.8 billion mu red line of plough was presented during the $4^{\text {th }}$ Session of the $10^{\text {th }}$ National People's Congress held in 2006 for the first time. The Third Plenary Session of the 18th Central Committee of the Communist Party of China (2012) illustrated five main directions: (1) Establishing a unified land market of both urban and rural area; (2) Improving the system for protection of land property rights; (3) Accelerating transformation of land managing function; (4) Optimizing the land-use system for sound urbanization development;(5) Establishing a complete system of natural resource. ${ }^{[3]}$ Therefore, the Chinese government is devoting to exploring a way to sustainably utilize land resources with Chinese characteristics under the overall strategic objective of building a moderately prosperous society in all respects.

SHUAI Wenbo (2012) analyzed the regulation and connotation about intensive utilization of land then concluded that the essence of land intensive use originates from an economic perspective. In this case, incentives of land economical and intensive utilization could be also from an economic mechanism. One important reason for the inefficient land use in China was the imbalance of interest policy with absence of relevant regulations. By analyzing contracture and conflicts of interests in China's land economical and intensive utilization system, the mechanism of land interest balance could be discovered and established with the security of relevant approaches on intensive land use.

DU Mingjun (2012) stated that China's land economical and intensive use policies were gradually evolving. But there were deficiencies from policies of China's economical and intensive land use, mainly including: failure to break through fetters of the extended development model, failure to build the perfect land requisition procedure, failure to form a reasonable process in the formation and allocation of the land revenue and so on. There were causes of policy shortcomings, mainly including: interest-driven local government in land use and economic development, vague definition on connotation of "public interest", extremely lack of organizational resources for vulnerable groups etc. Experts agreed that land policy innovation should focus on overall optimization planning, rationalization of examination and approval mechanism, fair market price management, fair compensation mechanism for sacrifice on "public interest", integration of urban and rural land asset management mechanism and rational supervision and monitoring mechanism with law enforcement etc.

HU chunxiang (2014) argued that major difficulties in current rural land intensive utilization included insufficient land supply from systematic bottleneck, vague land policies and alienation during implementation of policies etc. Therefore, it is urgently needed for refining the top-level policies in order to achieve effective and efficient use of land resources.

\section{The level of land intensive use and its influence on carbon emissions}

WANG Zhenshan (2015) selected 31 provincial cities in China as samples, using the multi-factor comprehensive analysis, fuzzy $\mathrm{G}$ type distribution and clustering analysis method etc. He drew a conclusion that only $19 \%$ of the total 31 cities have highly collaborative relations between land intensive utilization and ecological utilization. Most of the selected cities have a low collaborative condition. This conclusion showed that the intensive land utilization in China is still at an early stage and there is still a long way for china to achieve sustainable utilization of land.

HAN Feng (2013), on the basis of STIRPAT model, used the Feasible Generalized Least Squares method (FGLS) to analyze how industrial structure influences the level of land utilization. The results showed that urban land use intensification level respectively reflected significant $\mathrm{u}$-shaped and inverted u-shaped relationship from national level, with the improvement of industrial structure effect and competition effect. The improvement of influences between industrial structure 
and competition were conducive to the intensive utilization of land. On regional level, the industrial structure optimization of the eastern region had not yet reached the effective range for promoting intensive land use. The optimization of industrial structure in the central region was conducive to intensive land use; and the effect of industrial structure optimization on land use was not significant in the western region. Intensive utilization of urban land could benefit from impacts of regional industrial structure competition.

XU Hengzhou (2013) used econometric model to analyze the effects on carbon emissions from land market development and urban land intensive utilization. He has achieved two results: (1) the overall national land market development and the improvement of urban land intensive utilization had obvious impacts on slowing down carbon emissions; (2) During 1998-2011, for each 1\% increase on China's urban land intensive utilization level, carbon emissions were reduced by 1.906 units; and for each $1 \%$ increase on land marketization, carbon emissions were reduced by 1.528 units. ${ }^{[4]}$ He drew a conclusion that the government can improve the level of land marketization and urban land intensive utilization in order to reduce carbon emissions.

\section{The regional characteristics about changes of land intensive utilization}

KONG Wei (2014) argued that regional characteristics of land intensive utilization were due to regional differences in economic development and resource endowment. He used panel data of economic development and land use in Jiangsu province from 1998 to 2008. He came with two conclusions: (1) the increment of land intensive degree and the level of economic development both conformed to the EKC curve pattern. Along with economic development, investments in fixed assets demonstrated an accelerated upward trend at the beginning. Growth rate then slowed down with further economic development after per capita GDP exceeded 49045 yuan. ${ }^{[5]}$ The level of intensive land utilization then remained stable at the end. Due to various degrees of economic development transition point, the potential growth for land intensive utilization differs. (2) Four types of construction land control areas were identified in Jiangsu province according to the level of economic development and resource endowment. The optimized development area should combine with industrial structure adjustment to upgrade the land supply structure and strengthen three-dimensional exploitation of construction land. The key development area should strengthen the supply threshold of construction land and moderately add incremental construction land quota. The potential excavation area should raise the construction land supply threshold and reduce annual new construction land supply moderately. The moderate development area should focus more on improving land intensive use level to compensate land demand from costs of rapid urbanization and industrialization. The research results provided references on differentiated management of construction land.

Development zone is the primary carrier during China's industrialization stage. However the extensive use of land is severe and intensive utilization of land becomes the objective requirement for healthy development in economy and society through the process of construction and planning. WANG Chengxin (2014) analyzed intensive utilization land use in development zone by using the data of China's primary manufacturing province of Shandong with a construction of an evaluation system. The results showed that the overall condition of Shandong's development zone land intensive utilization was not ideal. Although the condition of land use was moderate, the rate of industrial land was at a low level and there were considerable regional differences. Land use intensity was weaker and input-output benefit was unsatisfactory. This was the primary reason why Shandong ranked first in resource consumption in China but still remained economically inefficient. Only $6.1 \%$ of all 164 development zone were in upper-intermediate intensity. ${ }^{[6]}$ It also demonstrated 
that the industrialization in Shandong was still at the stage of extensive development. A study found that the spatial distribution was more dispersive for development zones with highest intensity; the dispersion tended to increase for development zone with moderate and high-level intensive development zones; and less intensive development zone were located around the edge of Shandong province.

\section{Effective approaches and measures on land intensive use}

(1) Build a national strategy of land saving and intensive use. Establish a unified land market in urban and rural areas under the premise of overall planning. Implement a system of compensated use of collective construction land. Meanwhile improve wealth tax of land with supervision and evaluation mechanism on land saving and intensive use. Let farmers enjoy benefits as a result.

(2) Regionally differentiate control policies of intensive use of land: industrial structure upgrading transformation and construction land spatial development can be combined with regional development strategy for the area with higher level of economic development and little room for improvement in land intensive use. Supply threshold for new construction land should be raised in order to promote urban and rural construction land replacement for places where land for intensive use is large and resource endowment conditions is better.

(3) In response to problems of extensive land use and land wastage, ecological civilization concept should be addressed and cultivated at first. Then idle land needs to be overhauled in order to accelerate transformation from a single-resource based industrial structure to diversified industrial structure.

\section{References:}

[1] QIAN Lianlin, DONG Xin: The Land System Innovation and Guarantee in the Construction of New Countryside, Agricultural Economy (2006) P41-P43

[2] WANG Zhenshan, ZHANG Shaoliang, CHEN Fu, HOU Huping, ZHANG Jinhui, Zhao Jinmei: The Coordination Degree Between Urban Land Intensive and Ecological Utilization in China, Urban Problems No.11 (2015) P38-P44

[3] DONG Zuoji: Analysis the Trend of Land Policy after the Third Plenary Session of the 18th CPC Central Committee, China Land No.12 (2013) P8-P12

[4] XU Hengzhou, GUO Yuyan, CHEN Zongxiang: The Relationship Between Land Market Development, Urban Land Intensive Use and Carbon Emission: An Empirical Study Based on Provincial Panel Data in China, China Land Sciences Vol.27 No.9 (2013) P26-P29

[5] KONG Wei, GUO Jie, OU Minghao: Study on Land Intensive Use Response on Development and Regional Differentiated Control of Constructed Land, China population resource and environment Vol.24 No.4 (2014) P100-P106

[6] WANG Chengxin, LIU Hongyan, SHI Jialu, LIU Kai: Evaluation on Intensive Land Use in Development Zones of Shandong Province, China population, resource and environment Vol.24 No.6 (2014) P128-P133 